\title{
Recent Trends of Lung Cancer in Korea
}

\author{
Jae Guk Lee, M.D. ${ }^{1}{ }^{(\mathbb{D},}$ Ho Cheol Kim, M.D. ${ }^{1}$ and Chang-Min Choi, M.D., \\ Ph.D. ${ }^{1,2}$ (10
}

Departments of ${ }^{1}$ Pulmonary and Critical Care Medicine and ${ }^{2}$ Oncology, Asan Medical Center, University of Ulsan College of Medicine, Seoul, Republic of Korea

Lung cancer is one of the leading causes of cancer-related deaths in Korea. Although the smoking rate has decreased over time, the prevalence of lung cancer still remains high. In this study, we reviewed recent trends on the incidence, epidemiology, screening, diagnosis, and treatment of lung cancer in Korea by analyzing data from the national lung cancer registry and recently-published studies. Although approximately $40 \%$ of patients with non-small cell lung cancer (NSCLC) were diagnosed as stage IV, the 5-year relative survival rate improved from $11.3 \%$ (1993-1995) to 30.2\% (2013-2017), possibly due to advances in methods of diagnosis and therapy. In addition, the 2019 implementation of the national lung cancer screening program with low-dose computed tomography may have also contributed to these improvements in survival rates. Recently, molecular diagnosis has become more widely used in the identification of genetic mutations in tissue specimens. Target therapy and immune checkpoint inhibitors have also been successfully used, particularly in cases of advanced NSCLC. In the future, further research on the optimal management of lung cancer remains necessary.

Keywords: Lung Neoplasms; Epidemiology; Screening; Treatment; Korea

\section{Introduction}

Lung cancer is the most common cancer worldwide in terms of both incidence and mortality ${ }^{1}$. The situation is similar in Korea, where the crude incidence of lung cancer was the third highest among all cancers, according to the annual report of the Korean National Cancer Registration Statistics. In addition, lung cancer is the leading cause of cancer-related death in Korea ${ }^{2}$. A national lung cancer screening program

Address for correspondence: Chang-Min Choi, M.D., Ph.D.

Department of Pulmonary and Critical Care Medicine, Asan Medical Center, University of Ulsan College of Medicine, 88 Olympic-ro 43-gil, Songpa-gu, Seoul 05505, Republic of Korea

Phone: 82-2-3010-5902, Fax: 82-2-3010-5902

E-mail: ccm@amc.seoul.kr

Received: Nov. 17, 2020

Revised: Jan. 21, 2021

Accepted: Feb. 10, 2021

Published online: Feb. 10, 2021

(c) It is identical to the Creative Commons Attribution Non-Commercial License (http://creativecommons.org/licenses/by-nc/4.0/).

Copyright $\odot 2021$

The Korean Academy of Tuberculosis and Respiratory Diseases. using low-dose computed tomography was recently launched in Korea ${ }^{3}$, and various treatments such as target therapy and immune checkpoint inhibitors have been developed for lung cancer $^{4,5}$. Based on recent nationwide data, we have briefly reviewed the epidemiology, screening, diagnosis, and treatment of lung cancer in Korea.

\section{Epidemiology}

According to the Korea Central Cancer Registry, lung cancer was the third most common cancer $(11.6 \%, 26,985$ patients: $69 \%$ were male, and $31 \%$ were female) in 2017 after stomach and colon cancers ${ }^{6}$. The overall crude incidence rate was 52.7 per 100,000 population, and the age-standardized lung cancer incidence rate age-adjusted to the Korean standard population (Korean age-standardized incidence rate, KASIR) was 27.5 per 100,000 population in 2017 . The crude incidence and KASIR of lung cancer were higher in male patients (72.9 per 100,000 and 42.7 per 100,000 , respectively) than in female patients (32.5 per 100,000 and 15.8 per 100,000 , respectively) (Figure 1$)^{6}$. The incidence of lung cancer increased as both men and women aged, especially from the age of 65 years onwards. The KASIR of lung cancer also increased significantly with age and reached a peak at 80-84 years for men and a 

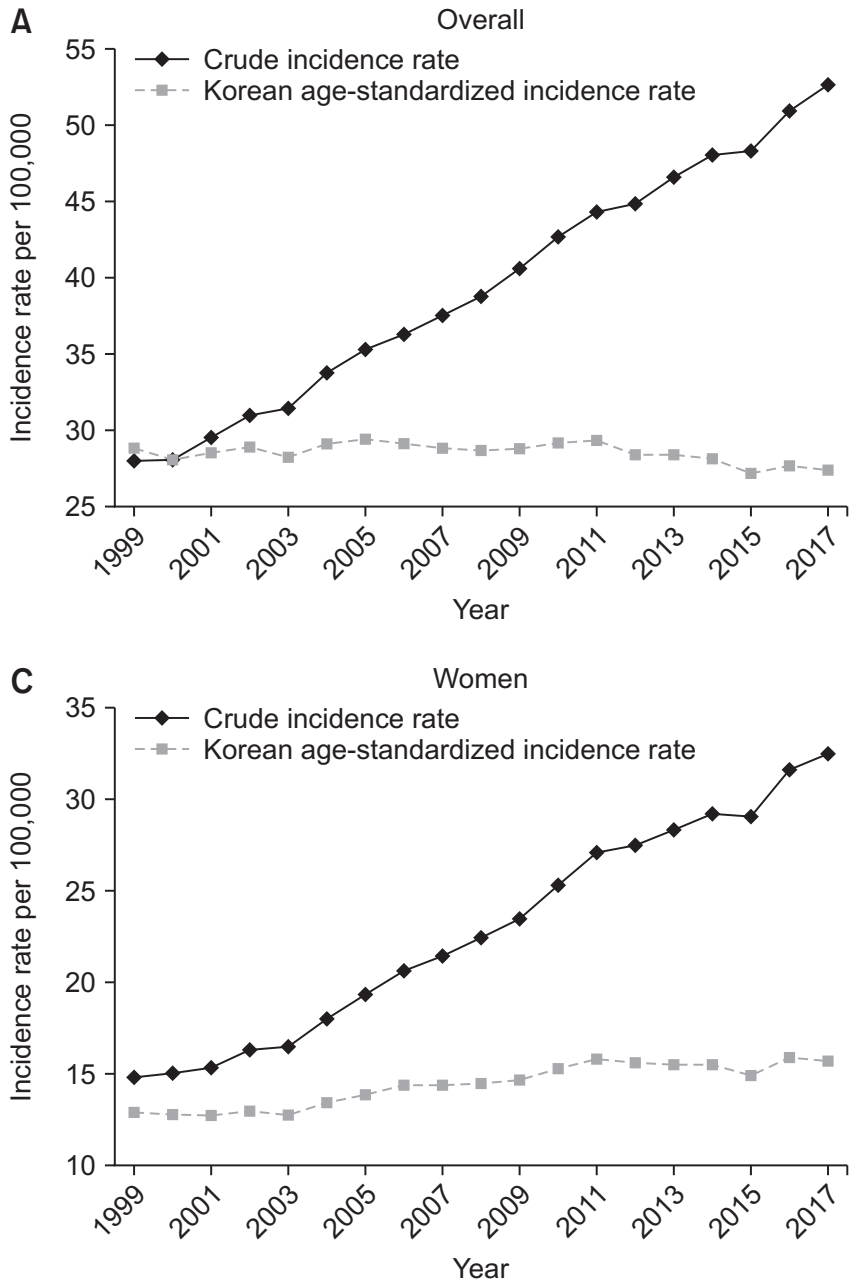

peak at 85 years for women ${ }^{6}$.

Until 2010, the most frequent histological type was squamous cell carcinoma in Korea. However, since 2011, adenocarcinoma has been the most commonly diagnosed cancer? These changes in the histology of lung cancer in Korea are the same as those observed for the global trend ${ }^{8}$. Additionally, adenocarcinoma in women is being diagnosed at a high rate, and this rate is increasing ${ }^{9,10}$. Especially in Asia, most female lung cancer patients are not smokers, and their histologic type is adenocarcinoma ${ }^{11}$. In addition, as observed for squamous cell carcinoma, the incidence of small cell carcinomas is decreasing (Figure 2) ${ }^{12}$.

At the time of diagnosis of lung cancer, the proportions of non-small cell lung cancer (NSCLC) patients in each clinical stage were as follows: $25.6 \%$ in stage I, $9.5 \%$ in stage II, $22.9 \%$ in stage III, and $42.0 \%$ in stage IV (Figure 3 ) $^{13}$. The prognosis of lung cancer differs according to the clinical stage, and the 5-year relative survival rate (2013-2017) was $69.0 \%$ for localized cancer, $39.3 \%$ for regional cancer, $7.7 \%$ for distant cancer, and $22.4 \%$ for unknown stage cancer ${ }^{6}$.

In 2017, the 5-year relative survival rate for lung cancer in

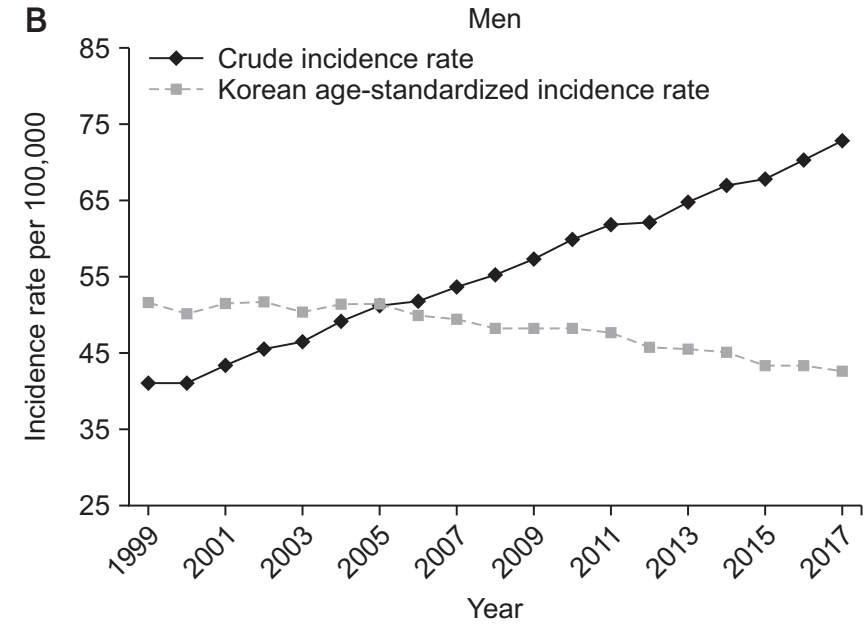

Figure 1. Trends in crude incidence rates and age-standardized lung cancer incidence rates per 100,000 in the Korean population: overall (A), men (B), and women (C).

Korea improved compared with the rate observed more than 10 years ago. Overall, the 5 -year relative survival rate of lung cancer in Korea increased from $16.5 \%(2001-2005)$ to $30.2 \%$ (2013-2017), with an increase from $15.3 \%(2001-2005)$ to $25.2 \%$ (2013-2017) in male patients and from 20.1\% (20012005) to $41.5 \%$ (2013-2017) in female patients (Figure 4$)^{6}$. The 5-year relative survival rate increase might be due to the reduction in the smoking rate ${ }^{14}$, advances in screening using imaging tools ${ }^{15,16}$, and the development of new chemotherapy approaches such as target therapy ${ }^{17}$.

\section{Screening}

The National Lung Screening Trial, which was conducted in the United States and used low-dose chest computed tomography (CT) for high-risk smokers, showed a $20 \%$ decrease in lung cancer mortality and $7 \%$ decrease in overall mortality, with a similar result in Europe ${ }^{15,16,18}$. Based on these results, Korea conducted the Korean Lung Cancer Screening Project (K-LUCAS). As a result, among the K-LUCAS participants, 79 

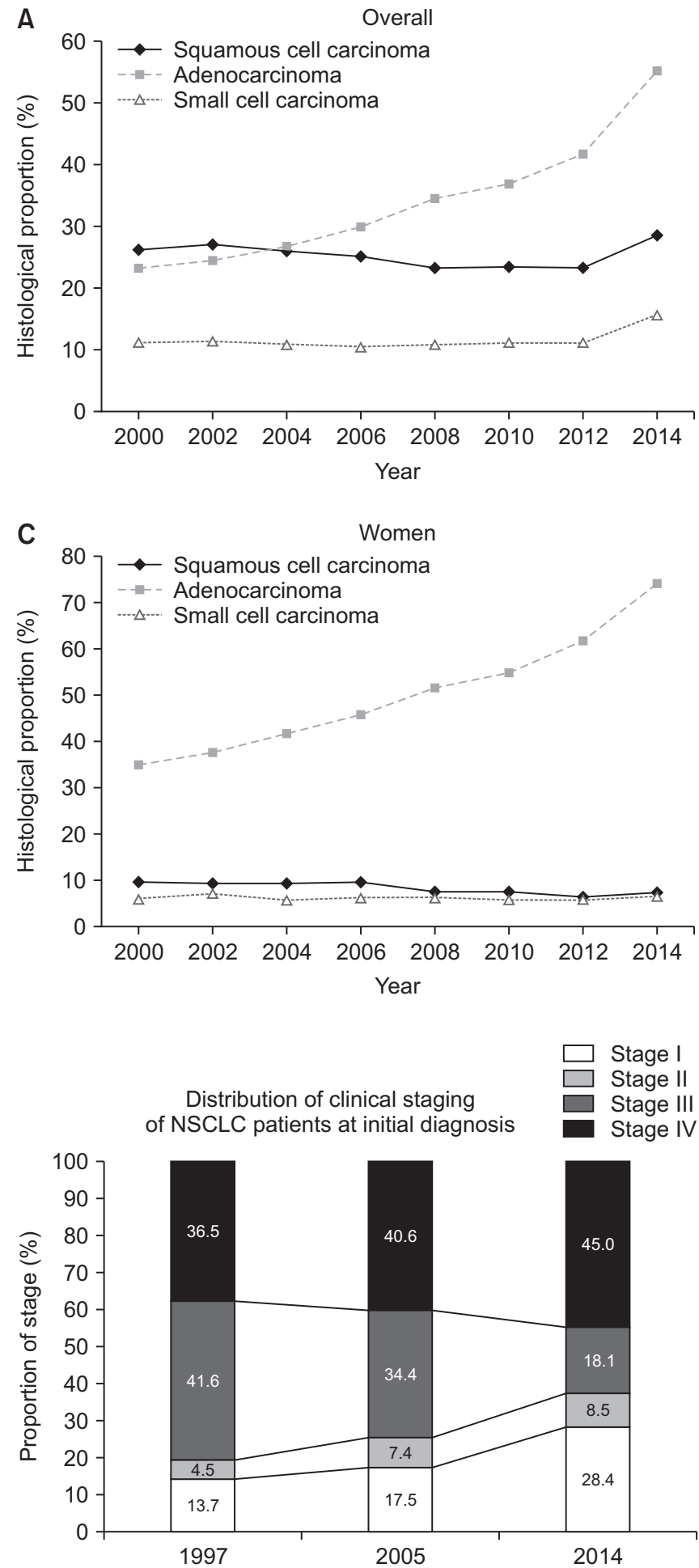

Figure 3. Distribution of clinical staging of non-small cell lung cancer (NSCLC) patients at initial diagnosis.

$(0.58 \%)$ were diagnosed with lung cancer, and among these 79,54 of patients (68.4\%) diagnosed early stage (stage I or II). This was evaluated to be three times higher than the early

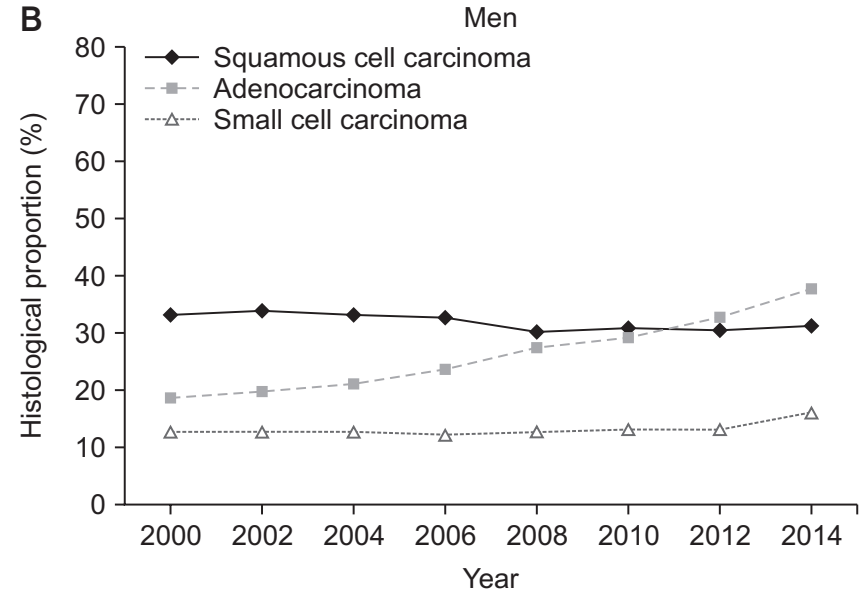

Figure 2. Trend in percent change in histological subtypes of lung cancer in Korea: overall (A), men (B), and women (C).

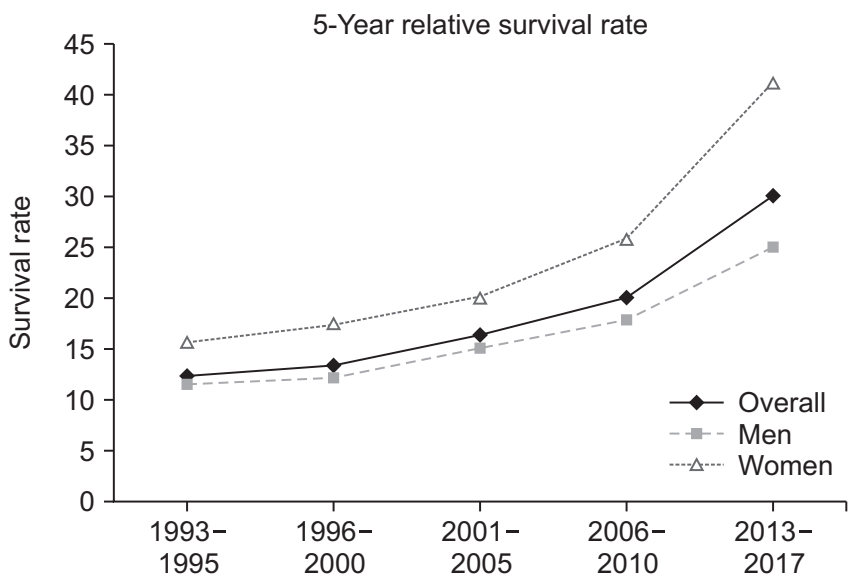

Figure 4. Trend in 5-year relative survival rate of lung cancer in Korea.

lung cancer diagnosis rate (21\%) among all registered lung cancer patients in Korea ${ }^{3}$. Thus, from August 2019, the world's first national health examination project was launched to detect lung cancer early through low-dose chest CT for high-risk smokers between 55 and 74 years of age, who smoked more than 30 pack-years. 
Table 1. Biopsy procedures for lung cancer

\begin{tabular}{|c|c|c|c|c|}
\hline Procedures & Advantages & Disadvantages & $\begin{array}{l}\text { Diagnostic } \\
\text { yield }(\%)\end{array}$ & $\begin{array}{l}\text { Pneumo- } \\
\text { thorax rate } \\
\quad(\%)\end{array}$ \\
\hline FBS & $\begin{array}{l}\text { High diagnostic yield for endobronchial } \\
\text { and central lesions }\end{array}$ & $\begin{array}{l}\text { Low diagnostic yield for peripheral lesion } \\
\text { and non-endobronchial lesions } \\
\text { Invasive; lack of expertise can cause } \\
\text { scratches in the laryngeal region and } \\
\text { airways. }\end{array}$ & $20-60$ & Rare \\
\hline CT-NAB & $\begin{array}{l}\text { The diagnostic yield is high for peripheral } \\
\text { lung lesions of more than } 2 \mathrm{~cm} \text { in } \\
\text { diameter. }\end{array}$ & $\begin{array}{l}\text { The patient's cooperation is required, } \\
\text { and it is difficult to collect tissue from } \\
\text { lesions in the center of the lung. }\end{array}$ & $77-94$ & $4.3-20$ \\
\hline EBUS-TBNA & $\begin{array}{l}\text { Tissues can be obtained from lung lesions } \\
\text { and lymph nodes in the center, and } \\
\text { ultrasound images can be checked in } \\
\text { real time. } \\
\text { Sampleable lymph nodes: located in } \\
\text { mediastinal, paratracheal, subcarinal, } \\
\text { hilar, and interlobar areas. }\end{array}$ & $\begin{array}{l}\text { Inability to obtain tissue from peripheral } \\
\text { lung lesions and lymph nodes except } \\
\text { the central lesion; invasive }\end{array}$ & $\begin{array}{l}\text { Sensitivity: } 90 \\
\text { NPV: } 93\end{array}$ & Rare \\
\hline EBUS-GS & $\begin{array}{l}\text { Compared to EBUS-TBNA, more } \\
\text { peripheral lung tissue can be obtained, } \\
\text { and ultrasound images can be checked } \\
\text { in real time. }\end{array}$ & Training is required. & 70 & 1 \\
\hline $\begin{array}{l}\text { Navigation } \\
\text { bronchoscopy }\end{array}$ & $\begin{array}{l}\text { Compared to EBUS-TBNA, more } \\
\text { peripheral lung tissue can be obtained, } \\
\text { and ultrasound images can be checked } \\
\text { in real time. }\end{array}$ & A navigation program is required. & $33-97$ & 3 \\
\hline ctDNA & $\begin{array}{l}\text { It is comfortable and less painful for } \\
\text { patients as it involves minimally invasive } \\
\text { procedures. } \\
\text { Serial monitoring is possible. }\end{array}$ & $\begin{array}{l}\text { ctDNA not present in all plasma samples } \\
\text { Very sensitive and specific methods of } \\
\text { isolation are required. } \\
\text { Some of the biomarkers available are } \\
\text { fragile. }\end{array}$ & $\begin{array}{l}\text { EGFR mutation: } \\
\text { Sensitivity } 62-75 \\
\text { Specificity } 80-95\end{array}$ & - \\
\hline
\end{tabular}

FBS: fiberoptic bronchoscopy; CT-NAB: needle aspiration biopsy with computed tomography guidance; EBUS-TBNA: endobronchial ultrasound-guided transbronchial needle aspiration; NPV: negative predictive value; EBUS-GS: endobronchial ultrasound using a guide; ctDNA: circulating tumor DNA.

\section{Diagnosis}

Imaging methods, such as $\mathrm{CT}$ and positron emission tomography-computed tomography, are necessary for the diagnosis and staging of lung cancer. In addition, bronchoscopy, CT-guided percutaneous needle aspiration (PCNA), and percutaneous needle biopsy (PCNB) are traditionally performed for the histologic diagnosis of lung cancer. Recently, endobronchial ultrasound bronchoscopy (EBUS) has made it easier to perform a biopsy on lung cancer lesions that are difficult to access with CT-guided PCNA and PCNB for central lung lesions ${ }^{19}$. Radial probe endobronchial ultrasound or navigation bronchoscopy has been introduced for peripheral lung lesions in an inaccessible position for EBUS-transbronchial needle aspiration, and it can replace CT-guided PCNA for biopsy ${ }^{20-22}$. Furthermore, a liquid biopsy method has been recently developed to detect circulating cell-free tumor DNA in the body fluid and blood of patients using quantitative realtime polymerase chain reaction, digital polymerase chain reaction, and next-generation sequencing (NGS). Liquid biopsy is expected to be used as a diagnostic tool for lung cancer in the near future (Table 1$)^{23}$.

Recently, molecular diagnosis has been implemented to identify mutant epidermal growth factor receptor $(E G F R)$, anaplastic lymphoma kinase $(A L K), R O S 1$, and $B R A F$, which might affect treatment and clinical outcome (Table 2) ${ }^{24}$. Korea has a high percentage of $E G F R$ mutations in adenocarcinoma (overall $29 \%$ to $50 \%$ ), similar to other Asian countries (overall $47 \%)^{25,26}$. Additionally, for women who are non-smokers in Korea, the rate of EGFR mutations in adenocarcinoma is particularly high ${ }^{27}$. These facts confirm that molecular diagnostics for lung cancer play a large role in the treatment of lung cancer in Korean women who have no smoking history. In the molecular diagnosis of lung cancer, the peptide nucleic acid- 
Table 2. Molecular markers for lung cancer in Korea

\begin{tabular}{|lll|}
\hline \multicolumn{1}{|c|}{ Molecular marker } & \multicolumn{1}{c|}{ Most common mutation } & \multicolumn{1}{c|}{ Approved medicine in Korea } \\
\hline EGFR mutation & Activating mutations: E19del, L858R & $\begin{array}{l}\text { 1st generation: gefitinib, erlotinib } \\
\text { 2nd generation: afatinib, dacomitinib } \\
\end{array}$ \\
3LK & Translocation: $E M L 4-A L K$ fusion & Alectinib, crizotinib, ceritinib, brigatinib \\
ROS1 & Translocation: $C D 74$, SLC34A2, CCDC6, FIG & Crizotinib \\
$B R A F$ & V600 mutation: V600E & Dabrafenib+trametinib \\
PD-1/PD-L1 expression & & Nivolumab, pembrolizumab, atezolizumab, durvalumab \\
\hline
\end{tabular}

EGFR: epidermal growth factor receptor; ALK: anaplastic lymphoma kinase; SLC34A2: solute carrier family 34 member 2; CCDC6: coiledcoil domain-containing protein 6; FIG: Golgi-associated PDZ and coiled-coil motif-containing protein; PD-1: programmed cell death protein 1; PD-L1: programmed death-ligand 1.

mediated clamping method is one of the most commonly used methods for detecting gene mutations in cancer tissue specimens in Korea ${ }^{4,28}$. Since 2017, an NGS technology-based genetic panel test has been designated for national health insurance benefits in Korean lung cancer patients, and it will be able to quickly identify mutant $E G F R, A L K, R O S$, and $B R A F^{29}$.

\section{Treatment}

There are three main treatments for lung cancer: surgery, radiation therapy, and chemotherapy. Treatment may vary depending on the histological findings, the stage of the disease, and the patient's condition. A previous study showed that $37.6 \%$ of patients initially diagnosed with NSCLC, regardless of stage, underwent surgery including adjuvant therapy; $8.3 \%$ of patients underwent radiation therapy only; $4.2 \%$ of patients underwent concurrent chemoradiotherapy (CCRT); $29.0 \%$ of patients received chemotherapy; and $12.8 \%$ of patients were provided supportive care without chemotherapy. $8.1 \%$ of patients were unknown (Figure 5) ${ }^{26}$.

Target therapy and immune checkpoint inhibitors (ICIs) have recently been administered for treatment, especially in advanced NSCLC (Table 2) ${ }^{5,30}$. According to one study, adenocarcinoma involves $E G F R$ mutations in $~ 50 \%$ of the cases; therefore, in Korea, EGFR should be tested, especially in adenocarcinoma ${ }^{31}$. In Korea, the Ministry of Food and Drug Safety has approved first-generation EGFR inhibitors (gefitinib and erlotinib) and second-generation EGFR inhibitors (afatinib and dacomitinib) as first-line therapy for adenocarcinoma after confirmation of EGFR mutation. When cancer proceeds despite these treatments, testing is performed for T790M mutation, and if found, osimertinib is recommended for therapy ${ }^{32}$. In addition, crizotinib, alectinib, and ceritinib, which are currently approved for use in Korea, can be considered as primary treatments when $A L K$ mutations are identified $(\sim 5 \%$ of NSCLC patients) $)^{33,34}$. Recently, the use of brigatinib was approved in Korea as first-line therapy in patients with NSCLC

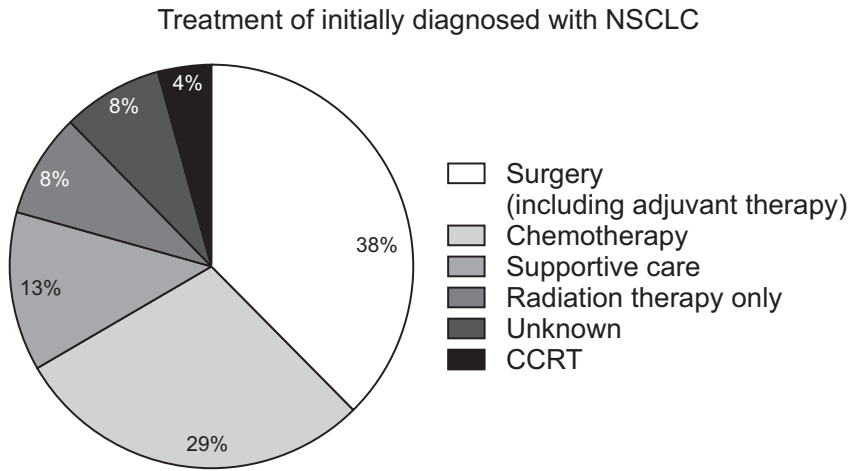

Figure 5. Current treatment of initially diagnosed with non-small cell lung cancer (NSCLC) in Korea. CCRT: concurrent chemoradiation therapy.

with $A L K$ mutation. Crizotinib has been approved as first-line therapy in Korea for cases in which ROS1 mutation is confirmed. Additionally, the use of a combination of dabrafenib and trametinib has been approved in Korea when there is a BRAF V600E mutation. ICIs-programmed cell death-1 protein (PD-1)/programmed dealth-ligand 1 (PD-L1) inhibitors such as nivolumab, pembrolizumab, atezolizumab, and durvalumab-can be used when the presentation of PD-1/ PD-L1 is confirmed in advanced NSCLC ${ }^{35}$. Nivolumab, pembrolizumab, and atezolizumab have been approved in Korea as salvage treatments for lung cancer patients who failed prior platinum-based chemotherapy. However, the approval conditions for administration are as follows: pembrolizumab is administered when PD-L1 expression $\geq 50 \%$ in lung cancer, nivolumab is administered when PD-L1 expression $\geq 10 \%$ in lung cancer, and atezolizumab is approved for administration irrespective of the level of PD-L1 expression in lung cancer. Durvalumab has been approved in Korea as consolidation therapy in patients with unresectable lung cancer of stage III with PD-L1 expression over 1\%, especially in patients without disease progression after CCRT. 


\section{Conclusion}

Lung cancer has the highest mortality rate among cancers worldwide. For this reason, among all countries, Korea was the first to conduct a national lung cancer screening program for high-risk lung cancer patients. Efforts are under progress to diagnose lung cancer more easily and quickly by introducing new diagnostic technologies. Additionally, precision medicine has been introduced, and many clinical trials are ongoing. Further large-scale studies are needed to investigate the optimal management of patients with lung cancer.

\section{Authors' Contributions}

Concept and design of the study: Lee GK. Kim HC, Choi CM. Manuscript writing: Lee GK, Kim HC. Writing - original draft preparation: Lee GK. Writing - review and editing: Kim HC, Choi CM. Approval of final manuscript: all authors.

\section{Conflicts of Interest}

No potential conflict of interest relevant to this article was reported.

\section{Funding}

No funding to declare.

\section{References}

1. World Health Organization. Cancer Fact [Internet]. Geneva: World Health Organization; 2018 [cited 2019 Nov 1]. Available from: https://www.who.int/news-room/fact-sheets/ detail/cancer.

2. Jung KW, Won YJ, Kong HJ, Lee ES. Cancer statistics in Korea: incidence, mortality, survival, and prevalence in 2016. Cancer Res Treat 2019;51:417-30.

3. Kim Y. Evidence of national lung cancer screening program in Korea. Korean J Health Promot 2019;19:161-5.

4. Park HJ, Lee SH, Chang YS. Recent advances in diagnostic technologies in lung cancer. Korean J Intern Med 2020;35: 257-68.

5. Jung CY, Antonia SJ. Tumor immunology and immune checkpoint inhibitors in non-small cell lung cancer. Tuberc Respir Dis 2018;81:29-41.

6. National Cancer Information Center. Annual report of cancer statistics in Korea in 2017. Goyang: National Cancer Center; 2020.

7. Shin A, Oh CM, Kim BW, Woo H, Won YJ, Lee JS. Lung cancer epidemiology in Korea. Cancer Res Treat 2017;49:616-26.

8. Lortet-Tieulent J, Soerjomataram I, Ferlay J, Rutherford M, Weiderpass E, Bray F. International trends in lung cancer incidence by histological subtype: adenocarcinoma stabilizing in men but still increasing in women. Lung Cancer 2014;84:1322.

9. Janssen-Heijnen ML, Coebergh JW. The changing epidemiology of lung cancer in Europe. Lung Cancer 2003;41:245-58.

10. Devesa SS, Shaw GL, Blot WJ. Changing patterns of lung cancer incidence by histological type. Cancer Epidemiol Biomarkers Prev 1991;1:29-34.

11. Dela Cruz CS, Tanoue LT, Matthay RA. Lung cancer: epidemiology, etiology, and prevention. Clin Chest Med 2011;32:60544.

12. Park CK, Kim SJ. Trends and updated statistics of lung cancer in Korea. Tuberc Respir Dis 2019;82:175-7.

13. Kim HC, Jung CY, Cho DG, Jeon JH, Lee JE, Ahn JS, et al. Clinical characteristics and prognostic factors of lung cancer in Korea: a pilot study of data from the Korean Nationwide Lung Cancer Registry. Tuberc Respir Dis 2019;82:118-25.

14. Doll R. The epidemiology of cancer. Cancer 1980;45:2475-85.

15. National Lung Screening Trial Research Team; Aberle DR, Adams AM, Berg CD, Black WC, Clapp JD, et al. Reduced lung-cancer mortality with low-dose computed tomographic screening. N Engl J Med 2011;365:395-409.

16. Oudkerk M, Devaraj A, Vliegenthart R, Henzler T, Prosch H, Heussel CP, et al. European position statement on lung cancer screening. Lancet Oncol 2017;18:e754-66.

17. Forde PM, Ettinger DS. Targeted therapy for non-small-cell lung cancer: past, present and future. Expert Rev Anticancer Ther 2013;13:745-58.

18. Pinsky PF. Lung cancer screening with low-dose CT: a worldwide view. Transl Lung Cancer Res 2018;7:234-42.

19. Sampsonas F, Kakoullis L, Lykouras D, Karkoulias K, Spiropoulos K. EBUS: faster, cheaper and most effective in lung cancer staging. Int J Clin Pract 2018;72:ee13053.

20. Tamiya M, Okamoto N, Sasada S, Shiroyama T, Morishita N, Suzuki H, et al. Diagnostic yield of combined bronchoscopy and endobronchial ultrasonography, under LungPoint guidance for small peripheral pulmonary lesions. Respirology 2013;18:834-9.

21. Gildea TR, Mazzone PJ, Karnak D, Meziane M, Mehta AC. Electromagnetic navigation diagnostic bronchoscopy: a prospective study. Am J Respir Crit Care Med 2006;174:982-9.

22. Eberhardt R, Anantham D, Herth F, Feller-Kopman D, Ernst A. Electromagnetic navigation diagnostic bronchoscopy in peripheral lung lesions. Chest 2007;131:1800-5.

23. Wu Z, Yang Z, Dai Y, Zhu Q, Chen LA. Update on liquid biopsy in clinical management of non-small cell lung cancer. Onco Targets Ther 2019;12:5097-109.

24. Suda K, Mitsudomi T. Racial differences in lung cancer genetics. J Thorac Oncol 2015;10:230-1.

25. Yatabe Y, Kerr KM, Utomo A, Rajadurai P, Tran VK, Du X, et 
al. EGFR mutation testing practices within the Asia Pacific region: results of a multicenter diagnostic survey. J Thorac Oncol 2015;10:438-45.

26. Choi CM, Kim HC, Jung CY, Cho DG, Jeon JH, Lee JE, et al. Report of the Korean Association of Lung Cancer Registry (KALC-R), 2014. Cancer Res Treat 2019;51:1400-10.

27. Park JY, Jang SH, Kim HJ, Park YB, Kwon JH, Song HH, et al. Predicting the treatment response using a direct sequencing method for EGFR in non-squamous, non-small cell lung cancer. Korean J Med 2011;81:611-22.

28. Lee HJ, Xu X, Kim H, Jin Y, Sun P, Kim JE, et al. Comparison of direct sequencing, PNA clamping-real time polymerase chain reaction, and pyrosequencing methods for the detection of EGFR mutations in non-small cell lung carcinoma and the correlation with clinical responses to EGFR tyrosine kinase inhibitor treatment. Korean J Pathol 2013;47:52-60.

29. Ministry of Health and Welfare. Notice 2017-19. Partial revision to details on criteria and method of application for medical care benefits [Internet]. Sejong: Ministry of Health and Welfare; 2017 [cited 2020 Feb 25]. Available from: http:// www.mohw.go.kr/react/jb/sjb0406vw.jsp.

30. Kim JS, Kang EJ. Targeted therapy for non-small cell lung cancer. Korean J Med 2020;95:78-88.

31. Min KW, Kim WS, Jang SJ, Choi YD, Chang S, Jung SH, et al. Comparison of EGFR mutation detection between the tissue and cytology using direct sequencing, pyrosequencing and peptide nucleic acid clamping in lung adenocarcinoma: Korean multicentre study. QJM 2016;109:167-73.

32. Mok TS, Wu YL, Ahn MJ, Garassino MC, Kim HR, Ramalingam SS, et al. Osimertinib or platinum-pemetrexed in $E G F R$ T790M-positive lung cancer. N Engl J Med 2017;376:629-40.

33. Park JY, Jang SH. Epidemiology of lung cancer in Korea: recent trends. Tuberc Respir Dis 2016;79:58-69.

34. Arbour KC, Riely GJ. Systemic therapy for locally advanced and metastatic non-small cell lung cancer: a review. JAMA 2019;322:764-74.

35. Kim HC, Choi CM. Current status of immunotherapy for lung cancer and future perspectives. Tuberc Respir Dis 2020;83:149. 